\title{
A Study of Rendering Metaphors in the Translation of the Titles of Persian Medical Articles
}

\author{
Neda Moradi ${ }^{1}$, Mohammad. Jafar JABBARI ${ }^{2}$ \\ ${ }^{1}$ MA Student, Islamic Azad University, Marvdasht Branch, Iran \\ ${ }^{2}$ Associate Professor of Linguistics, Yasouj University, Iran \\ n.moradi2112@gmail.com
}

\section{Abstract}

This study is an attempt to probe into the translation of metaphors in medical articles, to see whether the translators managed to render the same connotation of metaphors into English. This study covers some points for translating Persian metaphors into English through Newmark strategies (1988). As regards the most frequent strategy among the seven strategies proposed by Peter Newmark for translating metaphors, it was clarified that metaphors are rarely used in Iranian medical journals and cultural factors don't play an important role in translating. As a result, the researchers have come to the conclusion that titles as a text type may help improve medical academic literacy. This study is part of a growing body of research in the field. In using a largely untapped source of medical translation, this project will contribute to future research on similar topics. Also, the result of this study can be useful for medical and para-medical professionals, students, nurses and doctors in completing and updating their medical education and knowledge because they are the choicest readers of medical articles.

\section{Keywords}

Metaphor; medical articles;

Newmark's strategies;

cultural factor

\section{Introduction}

The extensive use of figures of speech is a dynamic phenomenon which enables us to generate new meanings from old in nearly all situations where we need to communicate and with respect to the importance of this notion, it is essential that translators attach their attention to the significant figures of speech, among which metaphor is the matter in question here. In 1993, Lakoff stated that "The word "metaphor" was defined as a novel or poetic linguistic expression where one or more words for a concept are used outside of their normal conventional meaning to express a similar concept" (p. 202). "In the cognitive linguistic view, metaphor is defined as understanding one conceptual domain in terms of another conceptual domain, and is written in the following way, DOMAIN A IS DOMAIN B, which is called conceptual metaphor" (Kovecses, 2002, p.4).

Metaphors play an important role in human thought and also in the creation of social, cultural, and psychological reality. In traditional theory you must have a special talent to be able to use metaphors, but Lakoff and Johnson (1980) in their study Metaphors We Live By claimed that metaphor is used in everyday life by ordinary people, not just by special talented people. They also claimed that metaphor is both in thought and everyday language.

Different languages will have different cultural and world views and this will be reflected through their metaphors, so translation of "metaphor" has been considered as a part of the more general problem of "untranslatability" so as Nuttall (1982), Ulijn (1985), and Carrell (1987) stated; metaphors are always potential problems for translators. According to Nelson - Herbert (1986), these words must be taught, not changed, or eliminated. There are 
many options in front of translators. The first option is literal translation; this translation may have been done word-for-word. As there are different kinds of metaphor, there are different strategies to render metaphor into target language. Some metaphors have equivalents in target language and in this case there is no difficulty in translation, but the problem emerges when there is no equivalent. In this case translators do not know whether they have to translate it literally, but it doesn't actually convey the intended meaning and misleads the readers, choose another metaphor, or render it into ordinary language. However, a "transcreation" translation would aim to make the original metaphor understandable in target culture. In most circumstances, a professional translator would recommend to not opt for a literal translation, because the intent is to make the translation not only well-written but also culturally relevant and looking as it had been originally written in the target language so the metaphoric choices are filtered in the cultural community the text is translated into.

Metaphor nowadays is an expressive literary agent studied in numerous fields; it is present in political, economical, scientific, art and other discourses. Much work has been done on metaphors in literary fields but few studies have been done in specialist area such as medical. In order to find out how medical concepts are structured in terms of metaphors, the metaphorical expressions found in a number of medical articles have been grouped.

\section{Review of Literature}

\subsection{Definitions of Key Terms}

\section{a. Figure of Speech}

The definition of a figure of speech is an expression that means something different from the literal meaning of the words. The Collins English Dictionary (2006) defines "figure of speech" as "an expression such as a simile, in which words do not have their literal meaning, but are categorized as multi-word expressions that act in the text as units". The language that uses figures of speech is called 'figurative language' and as Tajali (2003) stated that "its purpose is to serve three elements of clarity, forth and beauty in the language" (p.100). However, as any figure of speech has a figurative meaning, it may cause ambiguity which influences the clarity. Figurative language describes something which uses the unusual comparison, for the effect, interest, and to make it clearer. The use of figurative language makes sentences in literary works seem different from common sentences in literal meaning. Moreover, according to Abrams (1999, p. 96), "Figurative Language is a conspicuous departure from what users of language apprehend as the standard meaning of words, or else the standard order of words, in order to achieve some special meaning or effect." In figurative language, an expression may be used to refer to an idea or object that does not normally belong to the primary meaning of the object that the figure is used to refer to.

\section{Metaphor}

Kopp \& Craw (1998) defined that "The word metaphor derives from the Greek word metaphora; meta means 'over' and phora/pherein, means to carry" (p.307). Aristotle defined metaphor as "the application to one thing of the name of another thing". This traditional definition of metaphor had been used for centuries. Traditional views on metaphor, however, when Lakoff\& Johnson (1980) introduced a different approach to understanding and categorizing metaphor with their theory of conceptual metaphor. 


\section{b. Culture}

The word "culture" derives from a French term, which in turn derives from the Latin "colere," which means to tend to the earth and grow, or cultivation and nurture. One of the oldest definitions of culture, used by the Encyclopedia Britannica (1983, p. 657) is "that complex whole, which includes knowledge, belief, art, morals, law, customs, and other capabilities and habits acquired by the man as a member of society.

\section{c. Metaphor and Culture}

The translation of metaphors is strongly culturally conditioned. Therefore, the translation of metaphor, which is based on cultural factors, can be examined as a problem of theoretical and practical translation studies. Newmark (1988) seems to agree with this issue when he says: "whilst the central problem of translation is the overall choice of a translation method for a text, the most important particular problem is the translation of metaphor". A number of translation procedures for dealing with this problem have been suggested to translators: they can use an exact equivalent of the original metaphor; they can seek another metaphorical phrase which would express a similar sense (substitution); finally, they can replace an untranslatable metaphor of the original with its approximate literal paraphrase. Different cultures have different views on things because they are the characteristics and knowledge of a particular group of people who have different language, religion, science, social habits, music and arts, potentially leading to a changed meaning of the metaphor.

For Lederach, J.P. (1995) "Culture is the shared knowledge and schemes created by a set of people for perceiving, interpreting, expressing, and responding to the social realities around them" (p.9). Thus, it can be seen as the growth of a group identity fostered by social patterns unique to the group because each society will interpret a message in terms of its own culture. The receptor audience will decode the translation in terms of his/her own culture and experiences, not in terms of the culture and experiences of the author and audience of the original document. The translator must then help the receptor audience understand the content and intention of the source document by translation with both cultures in mind. The role of cultural context in translation in general (and metaphor translation in particular) has been notably highlighted by various scholars. Culturists such as Bassnett (1980) believes that the process of translation includes something more than mere "transfer of meaning contained in one set of language signs into another set of language signs through competent use of the dictionary and grammar" (p.13). In fact, no language can exist unless it is steeped in the context of culture and vice versa. As Nida (2001) states"the meaning of culturally dependent words is difficult to transfer in another language, particularlywhen the words are linked to cultural domains" (p.21). Thus, cultural factors play a crucial role in the manner in which metaphor is produced and translated in both ordinary and poetic language. Quinn (1987) states that metaphors are shaped and organized by some pre-existing cultural propositions which serve as cultural models. Although this approach was criticized by Lakoff and Kovecses (1987) claiming that cultural models themselves are metaphorical in nature.

Here the words "battle" and "fight" (as a transitive verb) could have a metaphorical meaning. One could argue that battle and fighting have meanings distinct from the ones here. Looking up the entries for battle and fight in an online dictionary, the Merriam-Webster Online, confirms this:

\section{Battle}

1: archaic: battalion

2: a combat between two persons 
3: a general encounter between armies, ships of war, or aircraft

4: an extended contest, struggle, or controversy

Battle can occur not only in a location like a combat between persons, armies, ships and aircrafts, but also in a mind activity (struggle). The question is here, why should battle be metaphorical? While its abstract meaning is listed in the dictionary.

\section{Fight}

1: a (1): to contend against in or as if in battle or physical combat (2): to box against in the ring

b (1): to attempt to prevent the success or effectiveness of < the company fought the takeover attempt $>(2)$ : to oppose the passage or development of <fight a bill in Congress >

2: (a): wage, carry on $<$ fight a battle $>$

(b): to take part in (as a boxing match)

3: to struggle to endure or surmount $<$ fight a cold $>$

4: (a): to gain by struggle <fights his way through>

(b): to resolve by struggle <fought out their differences in court>

5: (a): to manage (a ship) in a battle or storm

(b) : to cause to struggle or contend

(c): to manage in an unnecessarily rough or awkward manner

Here again the word fight is used in both meanings (concrete and abstract). Therefore, it is still questionable if these words are used in their primary or secondary meanings and if the phrase is therefore used literally or metaphorically. It seems that using a dictionary is not a satisfying criterion for translators, because one must decide which entry in the list is still a primary and which one is a secondary meaning. Goschler's recommendation (2007) is to establish scientific criteria to either determine the primary interpretation of a word without intuition or to establish the origin of the strong intuition.

The concept of priority in language acquisition was promoted by Johnson (1999), in order to identify the primary meaning of a word. This was based on children learning the primary definition of a word first. This does not resolve the issue of scientific language, which is not common in children's vocabulary. In 1990, Eve Sweetser introduced the concept of argument of historical priority to help identify the primary meaning of a word.

And in every language, there are words which their meanings were there first. Thus, it is difficult to claim a "primary" meaning of a word based on the order of dictionary entries, historic priority and priority of acquisition. Another distinction between primary and secondary meaning is often seen as identical to the distinction between concrete and abstract meaning. It seems to be a logical consequence to say that if a word is used in its abstract sense (as opposed to its concrete sense), and the concrete sense is used to structure the abstract domain, then the word is used metaphorically. As Goschler (2005) has shown different discourses can vary in what they treat as known and concrete and unknown and abstract. Not even the body is always "concrete": when it comes to medical explanations of diseases, cells, genes, or brain functions, these things are described in metaphors with source domains like war, communities, human beings, space and containers, technology, books, and others. Thus, if we accept the assumption that concrete versus abstract meaning is equal to literal versus metaphorical meaning, that seems to allow us to get a grip on many of the cases. But we need more than intuition in the metaphor analysis of scientific texts - the truth approach is not sufficient, i.e. the word meaning approach, would be a better basis for metaphor identification in scientific discourse. For a complete analysis of a certain scientific discourse, different approaches and cooperation with different disciplines seems absolutely 
necessary. Therefore, after a metaphor analysis of scientific texts, a critical reading of the texts themselves is necessary.

\section{d. Metaphors and Medical Concepts}

Any discipline has its own technical terms which represent technical concepts. When different writers refer to concepts by different terms (or refer to different concepts by the same term), students reading the works of different writers are easily confused. Terms ideally should be well motivated and should reflect the concepts clearly and be self-explanatory as much as possible. The most important thing is that a term in any language should represent a concept clearly and gain general acceptance. Picht \& Draskau (1985) offered a categorization of term-formation. They argued that any given language has a limited stock of words and morphemes available, and new terms are mostly formed in any language by giving old words new definitions (and in some cases new grammatical functions), by combining existing words or morphemes, or by borrowing a term from a foreign language. Thus, the terminology of medical disciplines poses a great challenge to any translator. It is due to the constant change and development in the language of medicine. New terms are added, other ones become redundant. Terminologists (C.K. Ogden and I.A. Richards, 1920s) propose a threefold relationship (known as the semantic triangle) between term, concept, and object. The term represents the concept, which is made explicit through definition, which is the term's extra linguistic referent. The concept is a mental representation of the object. A well-motivated term is one that represents the concept clearly, i.e., it includes or alludes to one or more of the features of the concept that may or may not figure in the definition. Here, metaphor is used to connect the relational pattern of a new experience with that of a familiar to understand and process a complex pattern in medical terminology. Hence, there are numerous difficulties translators have to face when translating medical texts. One of these difficulties is translation of terms and metaphors. As Broyard (1992) described; metaphor is a necessary tool to illness as it is to literature. He mentioned that metaphors are a relief from medical terminology. Thus, perhaps only metaphor can express the bafflement, the panic combined with beatitude, of the threatened person.

\section{e. Newmark's Metaphor Translation Procedure}

Scholars such as Newmark (1988) believe that translation is a change of linguistic form, and a translator should be well acquainted with lexicon, grammar and culture of the SL and TL to be able to analyze the ST and determine its meaning. As Newmark (1988) stated choosing the best strategy to translate metaphors closely depends on the types of metaphors. Therefore, he grouped (1988) different types of metaphors on the basis of their originality and boldness: dead, cliché, stock, adapted, recent and original. Here is an explanation about his classification as well as his suggested strategies to translate each type of metaphor:

A dead metaphor is one in which the sense of a transferred image is no longer present. A great number of ordinary vocabularies in any language are dead metaphors. They are often used when describing the time and space, geographical objects and activities of people. As a rule, the translator rarely has difficulty translating dead metaphors, but the problem is that it is not always possible to translate these metaphors literally. When translating dead metaphors, we should be guided by the principles of lexical combinability in the target language, i.e. dead metaphors of the original language should correspond equivalent dead metaphors of the target language. 
Newmark defined metaphors-clichés as metaphors that have temporarily outlived their usefulness; replace to obvious thoughts and are used only in connotative function, in order to express thoughts more clearly often with a larger share of emotions. The main obligation of the translator when facing cliché metaphors is to substitute it with its cultural equivalent in the TL. However, it can be replaced by a simile or even a dead metaphor when it has no suitable cultural equivalent.

Stock or standard metaphors are defined as established metaphors. They unlike dead metaphors have active aesthetic function. Standard metaphors are usually used in the informal contexts as a way of expressing a mental or physical situation that is the only noticeable difference between stock and cliché metaphors because there is not any clear distinction between them. Perhaps the only noticeable difference between these two types of metaphors is the style of the text within which they are applied. As Tetyana Oliynyk (2014) stated the translation of these metaphors can sometimes cause some difficulties for the translator, because the metaphor may be outdated (like the English expression it's raining cats and dogs) or be used only by members of a particular social class or age. The ideal solution would be to pick up the equivalent metaphor with a similar image in the target language, i. e, produce the SL image in the TL.

Metaphors which involve an adaptation of an existing (stock) metaphor called adapted metaphors this type of metaphor is actually a stock metaphor that has been adapted into a new context by its speaker or writer, and proverbs are included in this type of metaphors. The translators usually take great pains to do their best in the translation of this particular type of metaphor due to its magnificent cultural role in the TL because literal translation could not be clear to any of the speakers of other languages.

Metaphorical neologisms which have spread rapidly in original language called recent metaphors. Some metaphorical neologisms represent new concept. So we should be guided by principle of the translation of neologisms while their rendering.

Non-lexicalized and non-adapted metaphors are called original metaphors. This type of metaphor as defined by Newmark (1988, p. 112) "is created or quoted by the SL writer", and in the broadest sense, "contains the core of an important writer's message, his personality, his comment on life". Newmark stated original metaphors are not common in everyday usage. Because original metaphors are considered to be the individual author's metaphors used by the author individually, so they should be rendered as close as possible to the original.

\section{Research Method}

\subsection{Corpus and Materials}

Having decided to study the Persian-into-English translation of metaphors in medical discourse, the first criterion of selection was to find Persian medical articles whose titles have been translated into English. Besides the availability of English translation, there was another criterion used in choosing the corpus for this study: there should have been cultural-specific metaphors available which pose potential challenges in terms of cultural transfer.

This research focused on translating medical metaphors from Persian into English. The material of this study includes the titles of articles in all the issues of two journals (Tehran Medical Journal and Hamadan Medical Journal) published during five years. After selecting the journals, their titles were compared with their translation in English. The present corpus is based on comparing the source titles and their translations. All the issues were retrieved electronically and examined for the presence of metaphors in the titles. The titles were 
scanned for immediate comprehension and all candidates for being considered metaphors, so such investigation requires a model based on which the comparison should be made. In this research, the selected model is that of Peter Newmark (1988) who has proposed seven strategies for translating metaphors. After the metaphors and their translations were extracted and entered into a chart, then the frequency of un-translated and sometimes mistranslated forms were determined.

\subsection{Data Collection}

The methodology adopted by the researcher in the present study is a qualitative-cumdescriptive study to identify the most frequently used strategies applied by the Persian translators to translate metaphor from Persian into English..

The data selected came from the two medical journals published in Iran. The researcher collected the data from the source data, i.e. the metaphorical expression in Persian version and its translation. To collect the data, the researcher read both versions of titles to understand a general view of articles. After that the researcher wrote down the metaphorical expression and the translation then classifying the data into types of metaphor, analyzing the strategies used by the translator and identifying the metaphorical expression based on its translation accuracy.

The research methodology usually followed involves manually searching for metaphorical expressions in the titles and grouping them semantically under metaphor categories. Researcher examined the metaphorical entailments to determine a metaphor's dominant presence in the titles and its role in constructing specific ideologies and for this purpose she also read abstracts in order to get a better view of metaphors used in titles. The author of the source text communicated ideas via metaphors and the translator interpreted and transferred his interpretations into English. The research methodology involved identifying metaphorical expressions by hand, grouping them semantically under broad conceptual domains, and reflecting on the metaphors' entailments and the messages they convey, then it was examined whether metaphors were retained, developed, explicated, paraphrased or omitted in the target text (TT), making judgments about whether they were translated successfully, and determining whether metaphors served the same functions in the TT.

The data from the two journals under investigation produced a corpus of 736 articles) 519 ones in Tehran Medical Journal and 217 in Hamadan Medical Journal). A total of 80 Persian expressions were identified and analyzed.

As it was earlier stated, the aim of the present research was to find out how metaphors have been translated from Persian into English in the selected corpus. Therefore, this case study is an exploratory one in which the researcher tries to find out which strategies of translating are more applicable and beneficial. To achieve the said objective, medical articles, were selected as the source text. To investigate the translation of metaphors the source needed to be compared with its translations. Therefore, the corpus of the study is a "parallel corpus". According to Baker (2001), a parallel corpus consists of texts originally written in a language A, (here Persian), and their translation into language B, English in this research.

\subsection{Theoretical Framework}

Theoretical framework is the leading light of the way and benchmark of the results that are to be gained. This model maps the objectives of the study in a more abstract way and is intended to facilitate the visualization, understanding and analysis of the study. The mapping is done through highlighting the important features of the object. The theoretical models in 
translation studies are of three major categories of Process, Casual and Comparative. Selecting any of these models entails a review and reconsideration of research questions along with type and sort of data that has been selected. The research question of the study was whether translators have managed to render the appropriate equivalent of the metaphors of the source text and since this study focuses on the translations as products, the last model, which is static and product-oriented, becomes applicable. Following Williams and Chesterman (2002), this comparative model underlies the contrastive approach taken by translation studies scholars as Catford (1965) and Vinay and Darbelnet (1995). This model puts the two texts of source and target next to each other. Such comparison enables the researcher to investigate the equivalence of language use instances in terms of metaphors. Such investigation requires a model based on which the comparison should be made. In this research, the selected model is that of Peter Newmark (1988b) who has proposed seven strategies for translating metaphors as follows:

- Reproducing the same image in the TL;

- Replacing the image in the SL with a standard TL image which does not clash with the TL culture;

- Translation of metaphor by simile, retaining the image;

- Translation of metaphor (or simile) by simile plus sense, or occasionally metaphor plus sense;

- Conversion of metaphor to sense;

- Deletion;

- Translation of metaphor by the same metaphor combined with sense.

This model was the most comprehensive as well as detailed one that could be able to help the researcher to achieve the final purpose

\subsection{Data Analysis}

The researcher chose the corpus to show how Persian metaphor is translated into English in the selected body. Having selected medical articles as a primary source, the next step was to identify culture-specific terms and concepts of the text. To do so, a need for a framework was felt profoundly. As mentioned in the previous chapter, though many people know what culture means and they are cognizant of presence of cultural elements in their languages, they cannot pinpoint the culture-specific terms. So, this study was in a due need of a framework to be used as a reference, and based on it culture-specific terms and concepts were determined.

80 metaphors were found by the researcher. They were gathered in a table representing the source language metaphors, their translations and the strategies adopted by the translators in rendering Persian metaphors.

The metaphors were extracted and these extracts were analyzed within the above mentioned framework introduced by Newmark (1988). Every equivalent of the specified metaphors was studied based on this model and the strategy that the translator has adopted, was identified. Then the frequencies of the strategies were calculated one by one.

After calculating the frequency of each strategy, the percentage value was determined according to the table of frequency. These mounts were presented in different charts and diagrams. Finally, those strategies that have been used most by the translators were introduced as a framework for translators to benefit for their future translations of texts of the same type. 


\section{Discussion}

As many as 80 pieces of metaphors were collected by the researcher. The following table represents some examples of the source language metaphors, their translations and the strategies adopted by the translators in rendering the Persian metaphors. The full table is presented in appendix.

According to what ran before, the framework used to analyze the findings of the research is that of Newmark's. Then, his proposed strategies are presented based on his own numbered list. The same numbering is used for identifying the used strategy to save space and avoid the table jumbled. After that the frequency of each strategy is calculated for each translation according to which the percentage value is determined. These values are presented in different charts and diagrams, considering Newmark's proposed strategies as follows:

1. Reproducing the same image in the target language (TL) ("provided the image has comparable frequency and currency in the appropriate register"). This procedure is common for one-word metaphors like /mizban/ translated to "host".

2. Replacing the image in the source language (SL) with a standard target language (TL) image ("which does not clash with the target language culture").

3. Translation of metaphor by simile ("retaining the image"), for example, the English translation of / moraqebæt-e kangaroii / through this strategy is "Kangaroo Mother Care".

4. Translation of metaphor by simile plus sense ("or occasionally a metaphor plus sense") like the English translation of /tokmeh-e pusti / which is "skin tag".

5. Conversion of metaphor to sense. Regarding this strategy, it should be mentioned that when a metaphor is converted to sense, the sense must be analyzed componentially.

6. Deletion

7. Same metaphor combined with sense. For example, in translation of /hamel/ through this strategy, the translator added 'delivery' in its English translation (carriers).

Table 1. represents some samples of ST metaphors accompanied by their TT equivalents and the strategy used for translating them. The complete list of metaphors can be found at the appendix.

Table 1. Comparative Table of ST, TT and Translation Strategies of Metaphors

\begin{tabular}{|l|l|c|}
\hline \multicolumn{1}{|c|}{ ST Metaphors } & \multicolumn{1}{c|}{ TT Equivalents } & The Strategy used for Translating \\
\hline /fekæst-e dærman/ & treatment failure & Strategy 1 \\
\hline /qæfæsehsineh/ & chest & Strategy 5 \\
\hline /mizban/ & host & Strategy 1 \\
\hline /hamel/ & delivery carriers & Strategy 7 \\
\hline /quz-e qærnijeh/ & keratoconus & Strategy 5 \\
\hline /mæqz-eostexan/ & - & Strategy 6 \\
\hline /Tablehmorqan/ & Chicken pox & Strategy 5 \\
\hline /moraqebæt-ekangaroii// & Kangaroo Mother Care & Strategy 3 \\
\hline /mohadzem/ & Aggressive & Strategy 1 \\
\hline /tærmimpæzirij-e zæxm/ & wound repair & Strategy 2 \\
\hline /sezarijæn/ & cesarean delivery & Strategy 7 \\
\hline
\end{tabular}

This table is drawn up in order to represent the strategies employed by the translators in translating the metaphors. It should be noted that some of the translations cannot be matched 
with their original texts because they are completely different such as "آبره مرغان translated to "varicella". Seven strategies were found which had been used by the translators in translating the metaphors.

\subsection{The Frequency and Percentage of Strategies Used for Translating Metaphors}

Regarding the works of translators, the following results were achieved:

As can be seen from the table inserted in appendix, among the 80 metaphors found, these translators have reproduced the same image of SL metaphor in the TL in 38 occasions, replacing the image in the SL with a standard TL image which does not clash with the TL culture in 8 metaphors, translated the metaphor by simile, and translated the metaphor by simile plus sense, 1,2 metaphors respectively and also deleted the SL metaphor in four cases, 25 metaphors have been converted to sense, and finally two metaphors have been translated through the same metaphor combined with sense strategy. According to the above explanation, the first strategy, i.e. replacing the same image in the $T L$, has the most frequency. The descriptive statistics of the frequencies of using the seven strategies are presented in table 2 .

Table 2. Table of Frequency and Percentage of Strategies Used for Translating 80 metaphors.

\begin{tabular}{lcc}
\hline \multicolumn{1}{c}{ Strategy } & Frequency & Percentage \\
\hline $\begin{array}{l}\text { 1- Reproducing the same image in the target language } \\
\text { (TL) }\end{array}$ & 38 & $\mathbf{4 7 . 5 \%}$ \\
\hline $\begin{array}{l}\text { 2- Replacing the image in the source language (SL) } \\
\text { with a standard target language (TL) image }\end{array}$ & $\mathbf{8}$ & $\mathbf{1 0 \%}$ \\
\hline 3- Translation of metaphor by simile & 1 & $\mathbf{1 . 2 5 \%}$ \\
\hline 4- Translation of metaphor by simile plus sense & $\mathbf{2}$ & $\mathbf{2 . 5 \%}$ \\
\hline 5- Conversion of metaphor to sense & $\mathbf{2 5}$ & $\mathbf{3 1 . 2 5 \%}$ \\
\hline 6- Deletion & 4 & $\mathbf{5 \%}$ \\
\hline 7- Same metaphor combined with sense & $\mathbf{2}$ & $\mathbf{2 . 5 \%}$ \\
\hline Total & $\mathbf{8 0}$ & $\mathbf{1 0 0 \%}$ \\
\hline
\end{tabular}

The frequency of application of strategies used by translation is shown in figure 1 .

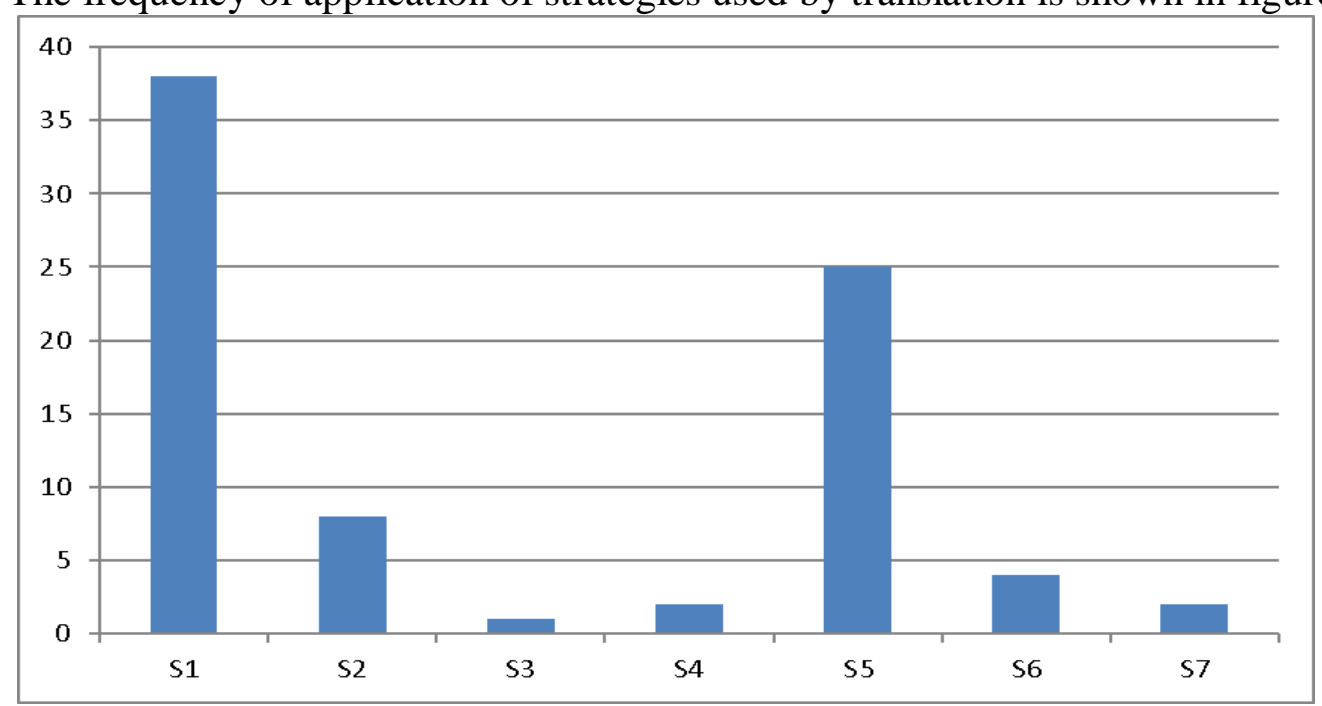

Figure 1. Frequency Bar Chart of Strategies Used in the Translation 
As can be depicted from table 2, replacing the same image in the TL is the strategy that has been applied in translation of metaphors with a frequency of occurrence of $47.5 \%$. After that, the strategy of conversion of metaphor to sense, is ranked on the second place with a frequency of $31.25 \%$. Then, replacing the image in the SL with a standard TL image which does not clash with TL culture with $10 \%$, translation by deletion with $5 \%$, translation of metaphor by the same metaphor combined with sense and translation by simile plus sense each with $2.5 \%$ are on the next ranks. Eventually, translation by simile has shared $1.25 \%$ of frequency. These data are better illustrated in figure 2 .

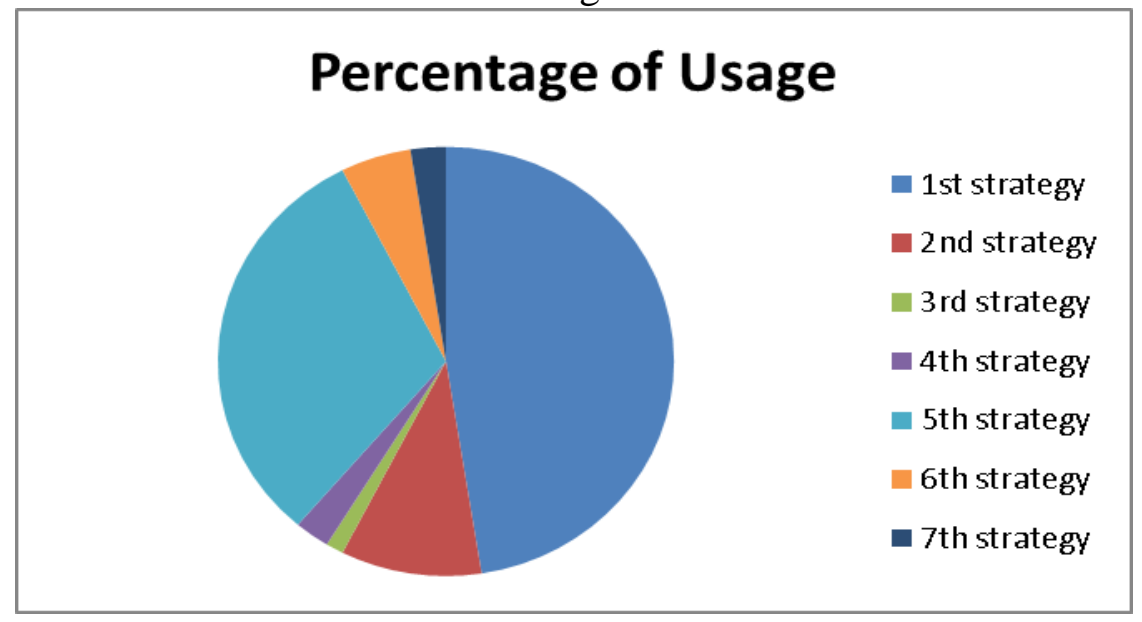

Figure 2. Percentage of Usage of the Seven Strategies in Translation

\section{Conclusion}

This study was an attempt to probe into the translation of metaphors in medical articles, to see whether the translators managed to render the same connotation of metaphors into English. Based on the questions set forth in the introduction, firstly an analysis was carried out of the strategies used by translators and subsequently using different tables and diagrams, the most applicable strategies were introduced.

Due to cultural differences between Persian and English speaking regions, it is so important to convey the cultural elements. This is applicable in the case of metaphors and culturally-bound expressions. In other words, if direct equivalents, i.e. the first and second strategies, for metaphors or cultural expressions are not available, paraphrasing would be acceptable to the target audience. However, there are fewer metaphors translated by strategy 2 in this research. To conclude, cultural differences did not prove to affect the translation of metaphors. The following factors might account for this result observed in a number of metaphors.

1. Medical sciences have tended through the course of history to maintain the Greek/Latin origin of the terms, so all these terms are fixed in approximately all languages.

2. Unlike the narrative quality of literary writing, medical language, like any scientific language, is basically descriptive. It thus much more frequently makes use of conceptexpressing nouns and descriptive qualifying adjectives.

Conducting research on other figures of speech such as personification, metonymy, allusion, irony etc. that have been heeded less can be more interesting. This study was delimited to the theoretical framework proposed by Peter Newmark (1988). A similar study can be carried out using another framework on translating medical metaphors and idiomatic expressions proposed by another scholar. 


\section{References}

Abrams, M. H. (1989). A glossary of Literary Terms. Harmondsworth: Earl McPeek.

Baker, M. (2001). The Routledge Encyclooedia of Translation Studies. London: Routledge.

Bassentt, S. (1980). Transaltion Studies. Routldge, New York.

Broyard, A. (1992). Intoxicated by Illness and Other Writings on Life and Death. New York, Ballantine books.

Carrell, P. L. (1987). Readability in ESL. Reading in a Foreign Language, 4(1), 21-44.

Goschler, J. (2005). Gehirnmetaphern - Verschiedene Formen der Metaphorisierung? .Linguistikim Schloss. Linguistischer Workshop Wartin, 25-34.

Kopp, R. R., \& Craw, M. J. (1998). Metaphoric language, metaphoric communication, and cognitive therapy. Psychotherapy: Theory, Research, Practice, Training, 35, 306-311.

Kovecses, Z. (2002). Metaphor: a Practical Introduction. New York: Oxford University Press.

Lakoff, G. (1993).The contemporary Theory of Metaphor. Retrieved from http://www. Theliterarylink.com/

Lakoff, G., \&Johnson, M. (1980). Metaphors We Live by. The university of Chicago press. Chicago.

Lakoff, G., \&Kövecses, Z. (1987) The Cognitive Model of Anger Inherent in American English, Cultural Models in Language and Thought. Cambridge University Press, 195221.

Lederach, J.P. (1995). Preparing for Peace: Conflict Transformation across Cultures. Syracuse University Press.

Newmark, P. (1981). Approaches to Translation. Oxford: Pergamon Press, London.

Newmark, P. (1988). A Textbook of Translation. New York, London: Prentice Hall.

Nida, E. A. (1964). Toward a Science of Translat $\neg i n g$. Leiden: E. J. Brill.

Nida, E.A. (2001). Contexts in Translating. John Benjamins Publishing Company.

Nuttall, C. (1982). Teaching Reading Skills in a Foreign Language. London: Heinemann Educational.

Oliynyk,T. (2014). Metaphor Translation Methods. International Journal of Applied Science and Technology, 4(1).

Picht, H., \&Draskau, J. (1985). Terminology: An Introduction. Guildford: University of Surrrey.

Ulijn, J. M. (1985). The scientific and technical register and its cross-linguistic constants and variants. UNESCO/ALSED Newsletter, 8(2), 148-158. 